\title{
INFERTILITAS SEBAGAI ALASAN KHULU, PERSPEKTIF ULAMA
}

\author{
Arif Marsal \\ Universitas Islam Negeri Sultan Syarif Kasim Riau \\ arif.marsal@uin-suska.ac.id
}

\begin{abstract}
In the Islamic Compilation Law in Indonesia that poured out in the constitution of the Republic of Indonesia number 1 year 1974, the definition and the aim of the marriage is stated in one article, which is in chapter 1 sets that the marriage is the bond of the inner birth between man and woman as a husband and wife, with the aim as to establish a household, a happy and everlasting family based on the belief of one and only God (KHI, Article 1 Chapter 1). However, the aim of the marriage is not easily to reach in. There are many issues come in that caused on an unsuccessful marriage. Furthermore, one of the issues that impact on the failure of the marriage is a husband's infertility. Moreover, the present of the child is one of the most noteworthy things in the marriage. Although, having a child is not a compulsory need, it has a big impact on the harmony of the household. That point has an impact on the assertion of the wife to lodge a khulu. That matter indubitable enticing to review from the Islamic law perspective.

Key Terms: Infertility, Khulu, Islamic scholar
\end{abstract}

\section{A. Pendahuluan}

Keputusan untuk menikah bagi pasangan yang saling mencintai bertujuan untuk merealisasikan kebahagian. Idealisasi tujuan perkawinan bagi semua pasangan nikah merupakan sesuatu yang wajar dan manusiawi. Hal itu sesuai dengan tuntutan Alquran QS. Ar Ruum: 21:

Artinya: "Dan diantara tanda kebesaran Allah adalah Ia menciptakan pasangan dari jenis kamu sendiri, agar kamu merasa tenteram kepadanya dan Allah menjadikan diantaramu cinta dan kasih sayang. Sesungguhnya pada yang demikian itu terdapat tanda-tanda kebesaran Allah bagi orang yang mau berfikir" (QS. Ar Ruum; 21). 
Dalam buku Ny. Soemijati, S.H., dikutip Idris Ramulyo disebutkan bahwa: tujuan perkawinan dalam Islam adalah untuk memenuhi tuntutan hajat tabiat kemanusiaan, berhubungan antara laki-laki dan perempuan dalam rangka mewujudkan suatu keluarga yang bahagia dengan dasar cinta dan kasih sayang, untuk memperoleh keturunan yang sah dalam masyarakat dengan mengikuti ketentuan-ketentuan yang telah diatur oleh syari'ah (Moh Idris Ramulyo, 1999:27).

Allah SWT memilihkan cara kepada manusia untuk mendapatkan keturunan adalah dengan jelas. Disyari'atkannya perkawinan telah jelas sekali dapat kita jumpai di dalam kitab suci Al-Qur'an (Abdul Haris Naim, 2008: 19).. Mulai dari adanya penegasan bahwa Allah SWT menciptakan makhluk hidup berjodoh-jodoh atau berpasang-pasang, baik dalam dunia manusia, binatang maupun tumbuh-tumbuhan, untuk memungkinkan terjadinya perkembangbiakan, guna melangsungkan kehidupan jenis masing-masing (Ahmad Azhar Basyir, 2000: 2).

Ayat tersebut memberikan penegasan bahwa tujuan perkawinan adalah agar diperoleh kebahagiaan lahir bathin. Suami mendapatkan kedamaian dan ketenteraman bersama isterinya dan sebaliknya isteri merasa damai dan nyaman bersama suaminya.

Menurut Undang-Undang Nomor 1 tahun 1974 Pasal 1, tujuan perkawinan adalah "Untuk membentuk keluarga (rumah tangga) yang bahagia dan kekal berdasarkan Ketuhanan Yang Maha Esa." (UU Perkawinan no.1, 1974 pasal1)

Membentuk keluarga artinya membentuk kesatuan masyarakat kecil yang terdiri dari suami, isteri dan anak-anak. Membentuk keluarga yang bahagia erat hubungannya dengan keturunan yang merupakan tujuan perkawinan, pemeliharaan dan pendidikan menjadi hak dan kewajiban kedua orang tua. Bahagia adanya kerukunan dalam hubungan antara suami isteri dan anakanak dalam rumah tangga.

Kehadiran anak menjadi salah satu tujuan utama disyari'atkannya perkawinan. Selain untuk regenerasi bisa diartikan sebagai upaya melestarikan gen manusia. Pernikahan sebagai sarana untuk memelihara gen manusia, alat reproduksi, dan regenerasi dari masa ke masa. Selain itu berkah dari do'a anakanak yang saleh kelak sepeninggalnya.

Tapi tidak semua pasangan memiliki keturunan. Ada sebagian mengalami Infertilitas atau gangguan kesuburan.

Yudisia, Vol. 9, No. 1, Jan-Jun 2018 
Sehingga tidak memiliki keturunan menimbulkan kerisauan dan persepsi negative terhadap pasangan. Muncul konflik bukan saja pada pasangan ini saja, tp terkadang merembet pada orang tua yang menuduh menantu mandul. Berdasarkan masalah di atas, penulis mencoba mengurai beberapa permasalahan. Apa Definisi Infertilitas? Apa itu Khulu? Apa dasar hukum Khulu'? Apa sajakah alasan Khulu' berdasarkan UU Perkawinan? Bagaimana gugatan cerai karena Infertilitas perspektif hukum Islam?

\section{B. Definisi Infertilitas}

Infertilitas, atau terkadang disebut kemandulan, adalah sebuah istilah dapat juga diartikan sebagai kegagalan, tidak berhasil, atau tidak dapat membentuk. Istilah infertilitas banyak digunakan pada bidang reproduksi yang dimaksudkan untuk membuahkan keturunan pada manusia maupun hewan. Reproduksi dilakukan melalui hubungan seksual antara pria dan wanita atau jantan dan betina.

Pada manusia, infertilitas mengistilahkan ketidakmampuan pasangan atau salah satu di antara pasangan untuk memiliki keturunan. Banyak faktor secara biologis yang dapat menyebabkan infertilitas, meskipun begitu hal tersebut dapat diobati dengan bantuan teknologi medis (https://id.wikipedia.org/wiki/Infertilitas).

Ketidaksuburan (infertil) adalah suatu kondisi dimana pasangan suami istri belum mampu memiliki anak walaupun telah melakukan hubungan seksual sebanyak 2 - 3 kali seminggu dalam kurun waktu 1 tahun dengan tanpa menggunakan alat kontrasepsi jenis apapun (Djuwantono,2008: 1).

Secara medis infertile dibagi menjadi dua jenis, yaitu:

a. Infertile primer

Berarti pasangan suami istri belum mampu dan belum pernah memiliki anak setelah satu tahun berhubungan seksual sebanyak 23 kali perminggu tanpa menggunakan alat kontrasepsi dalam bentuk apapun.

b. Infertile sekunder

Berarti pasangan suami istri telah atau pernah memiliki anak sebelumnya tetapi saat ini belum mampu memiliki anak lagi setelah satu tahun berhubungan seksual sebanyak $2-3$ kali perminggu tanpa menggunakan alat atau metode kontrasepsi jenis apapun. (Djuwantono, 2008: 2). 


\section{Definisi Khulu'}

Khulu (Bahasa Arab خلع) secara etimologi berarti "melepaskan". Sedangkan menurut istilah di dalam ilmu fiqih, khulu adalah permintaan cerai yang diminta oleh istri kepada suaminya dengan memberikan uang atau lain-lain kepada sang suami, agar ia menceraikanya.(https://id.wikipedia.org/wiki/Khulu)

Dalam Kamus Munawir "al Khal'u" secara etimologi berarti "al 'Azlu wan Naz'u" "melepaskan dan pencabutan". (Munawir, 361)

Khulu' adalah kesepakatan penceraian antara suami istri atas permintaan istri dengan imbalan sejumlah uang (harta) yang diserahkan kepada suami. (Mu'jam al washith, juz 1, 250) disebut juga fidyah dan iftida'. (Badawi, 2001: 326)

Tidak berbeda dengan talak, khulu' hukumnya pun bisa berubah menjadi mubah, sunnah, wajib, atau haram mngikuti hubungan suami istri itu sendiri. Adapun mengenai hukum bagi suami untuk menerima iwadh baik yang ditawarkan oleh istri atau karena permintaan suami sendiri hukumnya mubah. Ketentuan ini tampak adil kembali kepada dibangunnya akad yang diikuti dengan suami membayar maskawin, suami membayar nafkah, kemudian tiba-tiba ada semacam pengingkaran pihak istri.

Ini merupakan ciri khas khulu'. Artinya bila suami tidak mengaitkan pemutusan ikatan perkawinan yaitu cerai dengan adanya iwadh sama sekali tidak cerai itu termasuk talak. Mengenai jumlah harga iwadh memakai ukuran harga maskawin yang dibayarkan saat akad nikahnya. Hal ini diartikan tidak boleh kurang dari jumlah harga maskawin tanpa disetujui pihak suami, dan tidak boleh tanpa istri menyetujuinya.

Pasal 161 Kompilasi Hukum Islam berbunyi: "Perceraian dengan jalan khulu' akibat hukum khulu' adalah sama dengan talaq ba'in sugra yang artinya untuk kembali membangun rumah tangga harus melalui akad nikah yang baru.

\section{Dasar Hukum Khulu'}

Perceraian adalah perkara halal yang paling dibenci oleh Allah. Perceraian dipilih ketika dibutuhkan saja, yaitu apabila mempertahankan pernikahan akan mengakibatkan mudharat yang lebih besar. Dan jika tidak sangat diperlukan maka perceraian 
menjadi makruh karena mengakibatkan bahaya yang tidak bisa ditutupi.

Bagi wanita, meminta cerai adalah perbuatan sangat buruk. Dan Islam melarangnya dengan menyertakan ancaman bagi pelakunya, jika tanpa adanya alasan yang dibenarkan.

Dalam hadits riwayat Tsauban Nabi saw. bersabda, Artinya: "Wanita mana saja yang meminta kepada suaminya untuk dicerai tanpa kondisi mendesak maka haram baginya bau surga" (HR. Abu Dawud, kitab Thalaq, bab al khul'u, no. 2228 hal. 86-87).

Dalam hadits lain, dari Abu Hurairah ra., Rasulullah saw. bersabda,

Artinya: "Para wanita yang berusaha melepaskan dirinya dari suaminya, yang suka khulu' (gugat cerai) dari suaminya, mereka itulah para wanita munafiq." (HR. Nasa'i, kitab at thalaq, bab ma ja'a fil khul'I, 3461)

Dalam riwayat lain, dari Ibn Abbas ra.,

Artinya: "Bahwa Isteri Tsabit bin Qais bin Syammas mendatangi Nabi saw. seraya berkata; "Wahai Rasulullah, aku tidak membenci Tsabit dalam agama dan akhlaknya. Aku hanya takut kufur". Maka Rasulullah saw. bersabda: "Maukah kamu mengembalikan kepadanya kebunnya?". Ia menjawab, "Ya", maka ia mengembalikan kepadanya dan Rasulullah saw. memerintahkannya, dan Tsabit pun menceraikannya”. (HR. Bukhari, no. hadits 5274)

Ulama berbeda pendapat tentang hukum asal khulu', setidaknya ada tiga pendapat para ulama dalam hal ini:

Pertama, haram.

Hukum khulu' adalah haram jika dilakukan tanpa sebab tertentu. Seorang istri diharamkan meminta cerai kepada suaminya yang telah berbuat baik kepadanya dan menjalankan kewajibannya. Berdasarkan hadits diatas, "Wanita mana saja yang meminta cerai pada suami tanpa ada alasan maka haram baginya wangi surga." (HR. Abu Dawud, kitab Thalaq, bab al khul'u, no. 2228).

Hukum haram ini akan berubah menjadi boleh (mubah) dan disyari'atkan (masyru') apabila ada sebab-sebab tertentu yang membolehkan seorang wanita meminta khulu', seperti apabila 
terjadi kerdurhakaan di antara salah satu pasangan suami istri atau keduanya. Demikian ini adalah pendapat beberapa ulama tabi'in seperti Ibnu Sirrin dan Abu Qilabah. (Ibnu Qudamah, 6/74).

Kedua, mubah.

Seorang istri yang sudah tidak menyukai suaminya diperbolehkan untuk meminta cerai dengan menyerahkan mahar yang telah diberikan oleh suami. Hal ini karena dalil-dalil yang menjadi dasar disyari'atkannya khulu' menunjukkan pada nafyul junah (tidak berdosa). Dalam ilmu Ushul, para ulama menjelaskan bahwa nafyul junah menunjukkan pada hukum mubah/boleh, bukan dimakruhkan atau diharamkan.

Demikian ini adalah pendapat mazhab Hanafi dan beberapa ulama mazhab Maliki, hanya saja mereka mensyaratkan istri harus sudah baligh dan rasyidah; yakni sudah dewasa. Seorang istri yang masih kecil makruh baginya meminta khulu' kepada suaminya, dan seorang istri yang menderita penyakit bodoh haram baginya meminta khulu' kepada suaminya. (Ibnu Rusyd, 1995:1403)

Hadits Nabi tentang pengaduan istri Tsabit bin Qais menunjukkan tidak memaksa wanita untuk tetap bertahan dengan suaminya sekalipun dalam keadaan tertindas. Karena yang dilarang oleh Rasulullah saw. adalah melakukan gugat cerai tanpa alasan yang dibenarkan. Artinya, jika itu dilakukan karena alasan yang benar, syariat tidak melarangnya, bahkan dalam kondisi tertentu, seorang wanita wajib berpisah dari suaminya.

Ketiga, Makruh.

Khulu' hukumnya makruh karena melihat bahwa khulu'

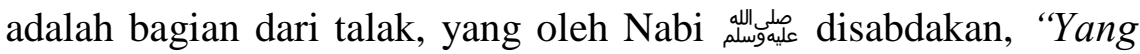
paling dibenci Allah dari sesuatu yang halal adalah talak." (HR. Abu Dawud).

Hadits ini menerangkan, kendati talak merupakan sesuatu yang disyariatkan dalam Islam namun ia juga sesuatu yang paling dibenci oleh Allah dari perkara-perkara yang diperbolehkan. Sehingga dalam syariatnya Islam menuntun untuk menjahui dari terjadinya perceraian.

Di antara yang berpendapat demikian adalah ulama dari kalangan mazhab Syafi'i dan Hanbali. Meskipun mereka menyatakan atas kemakruhannya namun mereka juga mengecualikan beberapa keadaan sehingga khulu' menjadi diperbolehkan. Di antaranya, apabila terjadi perselisihan antara 
suami-istri yang dikhawatirkan dengan kebersamaan mereka berdua justru akan membuat mereka tidak mampu menjalankan perintah-perintah Allah serta menjahui larangan-larangannya, atau apabila tidak memenuhi hak-hak suami istri yang telah diwajibkan oleh syari'at. Hal ini berdasarkan firman Allah swt, dalam surat Al Baqarah ayat: 229 di atas. (Al-Mawardi, juz 2:147)

Ibn Qudamah telah menyebutkan kaidah dalam hal ini, "Kesimpulan masalah ini, bahwa seorang wanita, jika membenci suaminya karena akhlaknya atau karena fisiknya atau karena agamanya, atau karena usianya yang sudah tua, atau karena dia lemah, atau alasan yang semisalnya, sementara dia khawatir tidak bisa menunaikan hak Allah dalam mentaati sang suami, maka boleh baginya untuk meminta khulu' (gugat cerai) kepada suaminya dengan memberikan biaya/ganti untuk melepaskan dirinya." (Ibn Qudamah, tt. Juz 16: 173).

\section{E. Alasan Penceraian berdasarkan UU Perkawinan}

Dalam hukum positif di Negara Indonesia, inisiatif perceraian dari pihak isteri disebut dengan cerai gugat, dimana seorang isteri mengajukan surat gugatan kepada ketua Pengadilan agar menceraikan dia dengan suaminya dengan salah satu atau beberapa alasan.

Berdasarkan Pasal 39 ayat (2) Undang-Undang No. 1 Tahun 1974 tentang Perkawinan (UU Perkawinan), untuk dapat melakukan perceraian harus ada cukup alasan bahwa antara suami dan isteri itu tidak akan dapat hidup rukun sebagai suami isteri.

Sedangkan, mengenai apa saja yang merupakan alasan-alasan perceraian, dapat dilihat pada dalam Kompilasi Hukum Islam (KHI) pasal 116, yaitu:

a. Salah satu pihak berbuat zina atau menjadi pemabok, pemadat, penjudi, dan lain sebagainya yang sukar disembuhkan;

b. Salah satu pihak meninggalkan pihak lain selama 2 (dua) tahun berturut-turut tanpa izin pihak lain dan tanpa alasan yang sah atau karena hal lain diluar kemampuannya;

c. Salah satu pihak mendapat hukuman penjara 5 (lima) tahun atau hukuman yang lebih berat setelah perkawinan berlangsung;

d. Salah satu pihak melakukan kekejaman atau penganiayaan berat yang membahayakan pihak yang lain; 
e. Salah satu pihak mendapat cacat badan atau penyakit dengan akibat tidak dapat menjalankan kewajibannya sebagai suami/isteri;

f. Antara suami dan isteri terus-menerus terjadi perselisihan dan pertengkaran dan tidak ada harapan akan hidup rukunlagi dalam rumah tangga. (Kompilasi Hukum Islam di Indonesia, 2001)

Selain alasan-alasan tersebut, di dalam Pasal 116 Kompilasi Hukum Islam juga diatur dua alasan perceraian yang tidak diatur dalam UU Perkawinan/PP Perkawinan yaitu:

a, Suami melanggar taklik talak;

b. Peralihan agama atau murtad yang menyebabkan terjadinya ketidakrukunan dalam rumah tangga."

Kemudian, dalam Pasal 16 PP Perkawinan dikatakan bahwa Pengadilan hanya memutuskan untuk mengadakan sidang pengadilan untuk menyaksikan perceraian apabila memang terdapat alasan-alasan seperti yang dimaksud dalam Pasal 19 PP Perkawinan dan Pengadilan berpendapat bahwa antara suami isteri yang bersangkutan tidak mungkin lagi didamaikan untuk hidup rukun lagi dalam rumah tangga.

Pada dasarnya, belum juga mempunyai anak bukan merupakan alasan yang sah secara hukum bagi suami-istri untuk melakukan perceraian.

(http://www.hukumonline.com/klinik/detail/lt5177845bd55d 4/tidak-bisa-punya-anak-sebagai-alasan-perceraian)

\section{F. Infertilitas Sebagai Alasan Khulu' Perspektif Ulama}

Polemik tentang kasus infertilitas,menarik untuk dikaji. Ulama berbeda pendapat boleh tidaknya mengajukan gugatan cerai.

Pertama, Infertilitas adalah cacat sebagai alasan untuk memberi pilihan kepada setiap pihak. Ulama yang berpendapat demikian adalah Ibn Sirin, Hasan, Muhammad bin Ibrahim dalam fatwanya, Sayyid Sabiq, Muhammad Shalih Utsaimi dan Abdullah bin Jibrain.

Pendapat diatas berdasarkan hadits riwayat Said bin Mansyur dalam "Sunan"nya, bahwa Umar bin Khatab radhiyallahu 'anhu, pernah mengutus seseorang sebagai petugas zakat di daerah tertentu. Ternyata dia menikah dengan wanita di daerah itu, padahal dia mandul. Umar-pun bertanya kepadanya, "Apakah kamu sudah memberi tahu istrimu bahwa kamu mandul, tidak bisa 
punya anak?" "Belum" Jawab orang ini. Umar menasehatkan, "Sampaikan kepadanya bahwa kamu mandul, kemudian berikan hak pilih untuknya." (Abdur Razaq, juz 6, hal. 162, hadits no. 10346)

Al Hasan berpendapat, apabila salah satunya Infertilitas maka diberikan pilihan. (Ibn Qudamah, tt, juz 10: 59)

Ibnl Qoyim dan sebagian ulama madzhab Hambali lainnya sependapat dengan Al Hasan, dimana salah satu pasangan suami istri berhak minta fasakh (gugat cerai ke pengadilan) karena mandul. Jika telah dipastikan suami atau istri orang yang mandul maka secara syariat, pasangannya dibolehkan untuk mengajukan fasakh, dan wajib bagi hakim untuk mengabulkan keinginannya, dalam rangka menghindari hal buruk yang terjadi. Jika tidak mungkin dilakukan fasakh maka istri boleh melakukan khulu' (gugat cerai ke suami), agar bisa berpisah denagn suaminya.

Kemudian, syarat bolehnya mengajukan fasakh, suami atau istri belum mengetahui cacat pasangannya ketika akad nikah. Suami atau istri ini menikah dan dia tidak tahu pasangannya mandul. Namun jika dia telah mengetahui hal itu, gugur haknya untuk mengajukan fasakh, karena ketika dia menjalani pernikahan, dia sudah memahami keadaan pasangannya, dan dia telah menggugurkan haknya sejak awal. Demikian yang dijelaskan para ulama.

Sayyid Sabiq berpendapat, seorang lelaki mandul yang menikahi wanita, dia tidak mengatehui kalau suaminya mandul, maka dia punya hak untuk mengajukan pembatalan nikah kalau dia mengetahuinya, kecuali apabila dia tetap rela menjadi istrinya. (Sayyid Sabiq, juz 2:191)

Oleh karena itu, tidak salah ketika seorang wanita mengajukan fasakh karena suami mandul, dengan harapan bisa menikah lagi dengan lelaki lain yang memungkinkan bisa mendatangkan keturunan melalui izin Allah. Hanya saja, dia juga perlu mempertimbangkan keadaan yang paling baik untuk kehidupannya dan kebahagiaannya. Menimbang dampak baik dan buruknya, dan memilih yang lebih mendatangkan manfaat, antara melanjutkan roda keluarga atau berpisah dengan suami.

Memang benar, bahwa aib adalah setiap yang menghalangi tujuan nikah, tidak perlu ragu, tujuan utama nikah adalah mut'ah, khidmat dan keturunan, apabila ada mani' maka itu aib, dengan 
demikian jika mendapati sumi infertil, atau istri infertil maka itu aib" (Shalih Utsaimin, 1420 H, juz 12: 220).

Muhammad Shalih Utsaimin juga menegaskan, "Istri tersebut berhak untuk minta cerai dari suaminya apabila nampak jelas bahwa kemandulan ada pada suaminya saja. Apabila suami mencerainya, maka itulah yang diinginkan. Namun apabila suami tetap tidak mau menceraikannya, maka hakim membatalkan nikahnya. Yang demikian itu dikarenakan wanita berhak untuk mendapatkan anak dan mayoritas wanita tidaklah menikah kecuali dikarenakan ingin memiliki anak. Maka, apabila laki-laki yang menikahinya mandul, dia berhak minta cerai dan membatalkan pernikahannya. Inilah pendapat yang rajih (kuat) menurut para ulama”. (Fatawa Al-Mar'ah hal. 347 Darul Ibn Hasyim, Koiro, cet. Ke-1, $1423 \mathrm{H})$

Syaikh Abdullah bin Jibrin berpendapat: "Tidak diragukan lagi bahwa mandul yaitu tidak adanya keturunan. Orang-orang terdahulu tidak menyebutkan sebab-sebabnya. Akan tetapi setelah adanya sarana pemeriksaan, nampak sebabnya adalah sedikitnya sperma dalam mani seorang laki-laki atau tidak ada sama sekali. Maka ini adalah mandul yang merupakan aib, jika sang istri tidak tahu (sebelumnya), maka boleh bagi istri meminta cerai karena ingin mempunyai anak keturuanan. Jika didapatkan pengobatan kedokteran yang sesuai syariat, yang bisa mengembalikan kekurangan (sperma) sehingga bisa menghasilkan keturunan. Maka sebaiknya ia tidak meminta cerai kecuali setelah melakukan usaha pengobatan dan (ternyata) tidak ada hasilnya. Wallahu a'lam. (Abdul Aziz Asy-Syitri, 40)

Kedua, Infertilitas bukan termasuk cacat, maka tidak boleh Khulu'

Sebagian Fuqaha' menyatakan bahwa Infertilitas suami bukanlah termasuk aib dalam pernikahan, oleh karena itu tidak diperbolehkan seorang istri meminta cerai kepada suaminya karena alasan Infertilitas. Alasannya adalah bahwa Infertilitas belum tentu bersifat permanen, dalam arti masih ada kemungkinan untuk sembuh. Namun meski Infertilitas bukanlah aib nikah sebelum aqad perlu adanya informasi dari masng-masing pihak agar dikemudian hari tidak trejadi percekcokan. Pendapat ini dikemukakan oleh Imam Syafi'I, imam Ahmad dan Imam Ibn Qudamah dari kalangan ulama salaf, sedangkan dari ulama 
kontemporer pendapat ini difatwakan diantaranya oleh Syeikh Athiyyah Shaqr.

Imam Syafi'I menyatakan, Jika lelaki menikahi wanita dia mengatakan saya mandul atau tidak mengatakan mandul sampai terjadi akad maka bagi wanita tidak ada khiyar (pilihan) ... mandul bukan alasan untuk khiyar (memilih), tapi tidak mampu jima' baru boleh khiyar, bukan tidak mampu punya anak. (Syafi'I, juz 5: 40)

Imam Ahmad memberikan statemen sebelum pernikahan dianjurkan untuk memberikan informasi kepada calon istrinya, kalo dia mengalami infertilitas. Tapi jika akad nikah sudah berlangsung, maka infertilitas bukan aib yang menghalangi pernikahan. (Masail Imam Ahmad, 1888-1887/4).

Syaikh Athiyyah Shaqar dalam (Fatwa al Azhar, juz 10: 89) menyatakan, Fuqaha sudah mendiskusikan aib apa saja yang memberi peluang kepada pasangan untuk berpisah, diantaranya penyakit kudis, kusta, gila, tersumbatnya seperma sehingga tidak bisa masuk ke farji wanita, ada sejenis benjolan seperti tanduk yang menghalangi jima'. Maka tiga imam madzhab selain Abu Hanifah sepakat, bahwa infertilitas pada wanita (dan laki-laki) bukan alasan untuk berpisah, karena kedua bisa saling mnikmati dalam prosesi jima'. Anak adalah karunia Allah). (Abu Malik Sa'id a; 'Isawi, www.wafa.com.sa/arabic/Subjects.aspx?ID=334)

\section{G. Kesimpulan}

Dari pemaparan di atas dapat disimpulkan, bahwa adanya infertilitas dalam kehidupan berumah tangga menimbulkan konskwensi hukum baru, yaitu boleh tidaknya mengajukan gugatan cerai. Dalam hal ini, ulama berbeda pendapat, sebagian menyatakan infertilitas adalah cacat yang bisa menjadi alasan untuk memberi pilihan kepada setiap pihak. Ulama yang berpendapat demikian adalah Ibn Sirin, Hasan, Muhammad bin Ibrahim dalam fatwanya, Sayyid Sabiq, Muhammad Shalih Utsaimi dan Abdullah bin Jibrain. Sebagian Fuqaha' menyatakan bahwa Infertilitas suami bukanlah termasuk cacat dalam pernikahan, oleh karena itu tidak diperbolehkan seorang istri meminta cerai kepada suaminya karena alasan Infertilitas. Karena Infertilitas belum tentu bersifat permanen dalam ada kemungkinan bisa sembuh. Pendapat ini dikemukakan oleh Imam Syafi'I, imam Ahmad dan Imam Ibn Qudamah dari 
kalangan ulama salaf, sedangkan dari ulama kontemporer pendapat ini difatwakan diantaranya oleh Syeikh Athiyyah Shaqr. 


\section{DAFTAR PUSTAKA}

Abdullah ibn Qudamah, Al Mughni, Darul Kitab al Arabi lin Nasyr wat Tauzi', tt.

Abdur Razaq, Mushannaf, Muhaqqiq Abdurrahman al A'dhami, Maktab al Islami, Beirut, $1403 \mathrm{H}$.

Abdul Haris Naim, Buku Daros Fiqh Munakahat, STAIN Kudus, Kudus, 2008.

Abu Dawud Sulaiman, Sunan Abi Dawud, kitab at Thalaq, bab al khul'i, Muassasah ar Rayyan, Beirut, 2004.

Abu Malik Sa'id a; 'Isawi, Dhahirah al Furqah bisabab adamil injab, ahkam wa hul" www.wafa.com.sa/arabic/Subjects.aspx?ID=334. Diakses 5 Agustus 2017

Ahmad bin Syuaib Nasa'I, sunan an Nasa'I, Beirut, Dar al Ma'rifah, tt.

Ahmad Azhar Basyir, Hukum Perkawinan Islam, UII Press Yogyakarta, Yogyakarta, Cetakan Kesebilan, 2000.

Ditjen Pembinaan Kelembagaan Islam Departemen Agama, 2001

Direktorat Pembinaan Peradilan Agama Islam, 2001. Kompilasi Hukum Islam di Indonesia.

Djuwantono, Tono,et.al.. Hanya 7 Hari Memahami Infertilitas. Bandung: PT. Refika Aditama, 2008.

https://id.wikipedia.org/wiki/Infertilitas http://www.hukumonline.com/klinik/detail/lt5177845bd55d4/tidakbisa-punya-anak-sebagai-alasan-perceraian. diakses 7 April 2017.

https://muslimah.or.id/3677-bolehkah-gugat-cerai-kerana-suamimandul.html diakses 7 April 2017.

https://muslimafiyah.com/meminta-cerai-karena-suamimandul.html. Diakses 5 April 2017

Ibrahim Abdul Aziz Asy-Syitri, Fatawa Al-Mar'ah, Darul Ibn Hasyim, Koiro, cet. Ke-1, $1423 \mathrm{H}$.

Muhammad bin Ismail al Bukhari, al Jami' al musnad as Shahih al Mukhtasar min Umuri Rasulillah saw wa sunanih wa ayyamih, Dar Thuqun Najah. $1422 \mathrm{H}$.

Moh Idris Ramulyo, Hukum Perkawinan Islam, Cetakan ke 2, PT Bumi Aksara, Jakarta, 1999. 
Muhammad shalih Utsaimin, Zadul Mustaqni' syarah mumti', Dar ibnl Jauzi lin Nasyr wat tauzi', Mamlakah Arabiyah Su'udiyah, 2000.

Muhammad bin Idris Asy Syafi'I, Al Umm', Nikah al 'anin wal khashiyy wal majbub, juz 5. Maktabah Syamilah.

Presiden Republik Indonesia, Undang-undang Republik Indonesia, Nomor i tahun 1974, Tentang perkawinan.

Sayyid Sabiq, Fiqih Sunnah, Cairo, Dar al Fath lil I'lam al Arabi, $1365 \mathrm{H}$. 